\title{
Impact of Primary Tumor Resection on Metastasis to the Lung in Patients With Bone and Soft-tissue Sarcoma
}

\author{
HIROYUKI TSUCHIE ${ }^{1}$, MAKOTO EMORI ${ }^{2}$, HIROYUKI NAGASAWA ${ }^{1}$, YASUTAKA MURAHASHI ${ }^{2}$, \\ EMI MIZUSHIMA ${ }^{2}$, JUNYA SHIMIZU ${ }^{2}$, TOSHIHIKO YAMASHITA ${ }^{2}$ and NAOHISA MIYAKOSHI ${ }^{1}$ \\ ${ }^{1}$ Department of Orthopedic Surgery, Akita University Graduate School of Medicine, Akita, Japan; \\ ${ }^{2}$ Department of Orthopedic Surgery, Sapporo Medical University School of Medicine, Sapporo, Japan
}

\begin{abstract}
Background: Few reports have investigated the effect of primary tumor resection on lung metastasis and prognosis in patients with bone and soft-tissue sarcoma, and we evaluated its effect on lung metastasis and prognosis. Patients and Methods: We retrospectively identified patients with lung metastasis from bone and soft-tissue sarcoma. We examined the factors affecting prognosis and the rate of lung metastasis increase. Results: A total of 48 patients were included. The multivariate analysis revealed that poor prognosis was significantly associated with a large maximum diameter of lung metastasis at the first visit and a rapid rate of increase ( $p=0.0400$ and $p=0.0003$, respectively). The multivariate logistic regression analysis revealed that the rate of increase of size of lung metastases was only significantly associated with a large maximum diameter at the first visit $(p=0.0245)$. Conclusion: Primary tumor resection of bone and soft-tissue sarcoma in patients with lung metastasis was not shown to affect their prognosis.
\end{abstract}

Bone and soft-tissue sarcomas, although relatively rare diseases, have various histological subtypes, including liposarcoma, synovial sarcoma, osteosarcoma, and Ewing sarcoma. Treatment is based on radical resection with adequate margins, regardless of the histological subtype, in order to prevent local recurrence. However, there is a consensus that the presence of distant metastases, particularly in the lungs, strongly influences prognosis (1-3). Chemotherapy is commonly used in patients with bone and

This article is freely accessible online.

Correspondence to: Hiroyuki Tsuchie (ORCID: 0000-0001-5011-7184), MD, Department of Orthopedic Surgery, Akita University Graduate School of Medicine, 1-1-1 Hondo, Akita 010-8543, Japan. Tel: +81 188846148, Fax: +81 188362617, e-mail: tuchikiti@yahoo.co.jp

Key Words: Sarcoma, lung metastasis, primary tumor, prognosis. soft-tissue sarcomas with lung metastases, especially those with numerous ones. The primary tumor is not aggressively resected in these patients. However, if the primary tumor interferes significantly with the patient's quality of life in terms of pain, neuropathy, and breaking of the skin, resection or even amputation may be required. Therefore, it is possible to remove only the primary tumor in these patients.

In recent years, prognosis has been shown to improve in certain malignancies, such as gastric and colorectal cancer with multiple metastases, when the primary tumor is removed (4-6). However, very few reports have investigated the effect of primary tumor resection on the prognosis of patients with bone and soft-tissue sarcomas with distant metastases $(7,8)$. Furthermore, to our knowledge, no reports have examined how excision of the primary tumor affects metastasis to the lungs, which is the most common type.

This study aimed to examine the impact of primary tumor resection on lung metastasis and prognosis in patients with bone and soft-tissue sarcoma.

\section{Patients and Methods}

Patients. We retrospectively identified patients with bone and softtissue sarcoma involving the extremities or trunk with lung metastasis at the first visit treated at our two hospitals between 1994 and 2020. Patients with lung metastasis confirmed at the same time as local primary tumor recurrence were also included. Since we aimed to assess the impact of primary tumor treatment, those who did not receive radiotherapy or surgical treatment for lung metastasis were also included. Patients' records were searched to collect data regarding age, sex, malignancy and histological subtype, anatomical tumor location, size, lung and other metastasis, primary tumor treatment, follow-up period, and outcomes. Specimens of soft-tissue sarcoma were classified using the French Federation of Cancer Center Sarcoma Group system, which includes the mitotic index, extent of necrosis, and histological differentiation (9). The maximum diameter and the number of lung metastases at the first visit were evaluated. In addition, the maximum diameter of lungmetastatic lesions in each of the first and last chest computed tomography images were measured, and the average rate of increase 
Table I. Comparison between patients based on surgical resection of the primary tumor.

\begin{tabular}{|c|c|c|c|c|}
\hline & & Surgical resection $(n=13)$ & Not resected $(n=35)$ & $p$-Value \\
\hline Age, years & Mean \pm SD & $44.0 \pm 27.5$ & $60.3 \pm 22.2$ & 0.0393 \\
\hline \multirow[t]{2}{*}{ Gender, $\mathrm{n}(\%)$} & Male & $8(61.5)$ & $17(48.6)$ & 0.6354 \\
\hline & Female & $5(38.5)$ & $18(51.4)$ & \\
\hline \multirow[t]{2}{*}{ Location, n (\%) } & Extremity & $7(53.8)$ & $24(68.6)$ & 0.5429 \\
\hline & Axial & $6(46.2)$ & $11(31.4)$ & \\
\hline Size of the primary tumor, $\mathrm{mm}$ & Mean \pm SD & $81.1 \pm 48.6$ & $118.7 \pm 69.6$ & 0.0807 \\
\hline \multirow[t]{2}{*}{ Tumor, n (\%) } & First time & $8(61.5)$ & $26(74.3)$ & 0.6127 \\
\hline & Recurrence & $5(38.5)$ & $9(25.7)$ & \\
\hline \multirow[t]{2}{*}{ Origin, $\mathrm{n}(\%)$} & Soft-tissue & $10(76.9)$ & $26(74.3)$ & 0.8513 \\
\hline & Bone & $3(23.1)$ & $9(25.7)$ & \\
\hline \multirow[t]{2}{*}{ Histological grade, $\mathrm{n}(\%)$} & Low & $1(7.7)$ & $2(5.7)$ & 0.6750 \\
\hline & High & $12(92.3)$ & $33(94.3)$ & \\
\hline \multirow[t]{3}{*}{ Number of lung metastases at first visit, $\mathrm{n}(\%)$} & $\leq 3$ & $6(46.2)$ & $12(34.3)$ & 0.3363 \\
\hline & $>3$ & $4(30.8)$ & $21(60.0)$ & \\
\hline & Unknown & $3(23.0)$ & $2(5.7)$ & \\
\hline Maximum diameter of lung metastasis at first visit, $\mathrm{mm}$ & Mean \pm SD & $7.5 \pm 3.7$ & $16.2 \pm 16.1$ & 0.0068 \\
\hline Average rate of lung metastasis increase, $\mathrm{mm} / \mathrm{month}$ & Mean \pm SD & $1.8 \pm 1.3$ & $4.8 \pm 5.9$ & 0.0142 \\
\hline \multirow[t]{2}{*}{ Distant metastasis other than lung at the first visit, $\mathrm{n}(\%)$} & Yes & $4(30.8)$ & $9(25.7)$ & 0.9879 \\
\hline & No & $9(69.2)$ & $26(74.3)$ & \\
\hline \multirow[t]{2}{*}{ Distant metastasis other than lung that appeared later, $\mathrm{n}(\%)$} & Yes & $1(7.7)$ & $4(11.4)$ & 0.8768 \\
\hline & No & $12(92.3)$ & $31(88.6)$ & \\
\hline \multirow[t]{2}{*}{ Radiation for primary tumor, $\mathrm{n}(\%)$} & Yes & $5(38.5)$ & $11(31.4)$ & 0.9086 \\
\hline & No & $8(61.5)$ & $24(68.6)$ & \\
\hline \multirow[t]{2}{*}{ Chemotherapy, n (\%) } & Yes & $7(53.8)$ & $21(60.0)$ & 0.9562 \\
\hline & No & $6(46.2)$ & $14(40.0)$ & \\
\hline Follow-up period, months & Mean \pm SD & $17.8 \pm 11.5$ & $12.6 \pm 12.2$ & 0.1915 \\
\hline \multirow[t]{2}{*}{ Status at the last follow-up, n (\%) } & Alive with disease & $2(15.4)$ & $4(11.4)$ & 0.9023 \\
\hline & Dead & $11(84.6)$ & $31(88.6)$ & \\
\hline
\end{tabular}

per month (mm/month) was defined. We additionally collected information regarding the type of local therapy and surgical margins (Enneking staging system) for patients who underwent surgery (10). In the absence of any events, patients were censored at the last follow-up. Overall survival (OS) was defined from the date of diagnosis to the date of death or the last follow-up.

Clinical characteristics and outcomes were compared based on primary tumor resection status, and the factors affecting prognosis were examined. In addition, we evaluated the factors affecting the average rate of increase in the size of lung metastases.

Statistical analysis. All continuous variables were expressed as the mean \pm standard deviation. Student's $t$-tests, Welch $t$-tests, and chisquared tests were used to compare characteristics between the two groups. A Cox proportional hazards model was used to identify the factors that were associated with OS. OS was compared using the Kaplan-Meier method, and differences were analyzed using the generalized Wilcoxon test.

We were able to measure the rate of increase in size of lung metastases more than once in 39 of the patients. The mean rate was $4.08 \pm 5.37 \mathrm{~mm} / \mathrm{month}$ (range $=-0.2-29.2 \mathrm{~mm} / \mathrm{month}$ ) and the patients were divided into fast and slow increase groups based on this average. Multivariate logistic regression analysis was used to examine the factors associated with the rate of lung metastasis size. A $p$-value of less than 0.05 was used to denote statistical significance.
Ethics. This study was approved by the Institutional Review Board for Clinical Research at the Akita University (approval number: 2636) and was conducted in accordance with the 1975 Declaration of Helsinki and its 1983 revision.

\section{Results}

A total of 48 patients with bone and soft-tissue sarcoma were included in this study, 25 of whom were male and 24 were female. The mean age was 55.9 years (range $=10-91$ years),

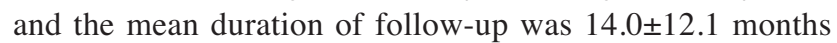
(range $=1-46$ months). The histological diagnoses of softtissue sarcoma were malignant peripheral nerve sheath tumor in eight, undifferentiated pleomorphic sarcoma in seven, synovial sarcoma in six, dedifferentiated liposarcoma in four, myxoid liposarcoma in two, pleomorphic liposarcoma in one, leiomyosarcoma in two, epithelioid sarcoma in two, extraosseous Ewing sarcoma in two, myxofibrosarcoma in one, and alveolar rhabdomyosarcoma in one. The histological diagnoses of bone malignant tumors were conventional osteosarcoma in seven, small-cell osteosarcoma in one, chondrosarcoma in two, and Ewing sarcoma in two. 
Table II. Univariate and multivariate analyses of potential prognostic predictors.

\begin{tabular}{|c|c|c|c|c|c|c|}
\hline \multirow[b]{2}{*}{ Factor } & \multicolumn{3}{|c|}{ Univariate } & \multicolumn{3}{|c|}{ Multivariate } \\
\hline & OR & $95 \% \mathrm{CI}$ & $p$-Value & OR & $95 \% \mathrm{CI}$ & $p$-Value \\
\hline Age & 1.000 & $0.988-1.012$ & 0.9604 & & & \\
\hline Gender (female) & 1.197 & $0.641-2.238$ & 0.5725 & & & \\
\hline Location (axial) & 0.736 & $0.375-1.444$ & 0.3733 & & & \\
\hline Size of the primary tumor & 1.003 & $0.999-1.008$ & 0.1598 & & & \\
\hline Local recurrence & 0.598 & $0.302-1.185$ & 0.1405 & & & \\
\hline Malignant bone tumor & 1.026 & $0.504-2.089$ & 0.9428 & & & \\
\hline Histological grade (high) & 1.579 & $0.869-2.870$ & 0.1335 & & & \\
\hline Maximum diameter of lung metastasis at first visit & 1.039 & $1.017-1.062$ & 0.0005 & 1.028 & $1.001-1.056$ & 0.0400 \\
\hline Number of lung metastasis at first visit $(>3)$ & 1.575 & $0.794-3.124$ & 0.1939 & & & \\
\hline Distant metastasis other than lung at the first visit & 1.044 & $0.520-2.039$ & 0.9042 & & & \\
\hline Surgical treatment for primary tumor & 0.738 & $0.367-1.482$ & 0.3926 & & & \\
\hline Inadequate surgical margins & 1.974 & $0.504-7.728$ & 0.3289 & & & \\
\hline Radiation for primary tumor & 0.988 & $0.522-1.869$ & 0.9703 & & & \\
\hline Chemotherapy & 1.145 & $0.601-2.181$ & 0.6812 & & & \\
\hline Average rate of lung metastasis increase & 1.156 & $1.075-1.242$ & $<0.0001$ & 1.149 & $1.066-1.238$ & 0.0003 \\
\hline Distant metastasis other than lung that appeared later & 1.117 & $0.392-3.180$ & 0.8364 & & & \\
\hline
\end{tabular}

CI: Confidence interval; OR: odds ratio.

The sites these primary lesions were the extremities in $64.6 \%$ $(\mathrm{n}=31)$ and axial sites in $35.4 \%(\mathrm{n}=17)$. The mean tumor size was $108.5 \pm 66.3 \mathrm{~mm}$ (range $=25-370 \mathrm{~mm}$ ), and histological grade was low in three and high in 45 patients.

The mean maximum diameter of lung metastases at first visit was $14.1 \pm 14.6 \mathrm{~mm}$ (range $=2-80 \mathrm{~mm}$ ) and 30 patients $(27.1 \%)$ had already developed them in the bones in seven cases, lymph nodes in four, liver in three, intraperitoneal space in two, brain in one, and the stomach in one. In addition, five patients $(10.4 \%)$ developed extra-pulmonary metastasis later, four in bone, and in a lymph node in one, pancreas in one, adrenal gland in one, and the thoracic cavity in one.

Surgical treatment for the primary tumor was performed in 13 patients $(27.1 \%)$, and adequate tumor-free margins were achieved in six of these. Radiotherapy for the primary tumor was performed in 16 patients $(33.3 \%)$, which included protonbeam radiation $(6.3 \%, \mathrm{n}=1)$ and radiotherapy plus surgery $(25.0 \%, \mathrm{n}=4)$. Chemotherapy was administered to 28 patients $(58.3 \%)$ and included doxorubicin, ifosfamide, dacarbazine, gemcitabine, docetaxel, methotrexate, cisplatin, carboplatin, vincristine, cyclophosphamide, etoposide, actinomycin D, eribulin, trabectedin, and pazopanib. In terms of outcomes, six patients were alive with the disease and 42 patients had died because of it at the last follow-up. No patients died due to complications during the perioperative period.

Patients who had their primary tumor resected had significantly smaller lung metastases at the first visit and a slower rate of increase than those who did not undergo surgical resection ( $p=0.0068$ and $p=0.0142$, respectively) (Table I). The multivariate analysis revealed that the maximum diameter of lung metastases and the average rate of increase were significant prognostic predictors $(p=0.04$ and $p=0.0003$, respectively), yet primary tumor resection did not affect the outcome (Table II). The Kaplan-Meier curve revealed that patients with slow-growing lung metastases had a significantly better prognosis than those with fast-growing ones $(p=0.0003)$ (Table III and Figure 1).

Patients in the fast-growing group had a significantly larger maximum diameter of lung metastasis at the first visit $(p=0.0419)$ (Table IV). The multivariate logistic regression analysis revealed that the rate of increase was significantly associated with the maximum diameter of lung metastasis at the first visit $(p=0.0245)$ and that surgical resection of the primary tumor did not affect the rate of increase (Table V).

\section{Discussion}

This study found that patients whose primary tumor was resected were significantly more likely to have smaller lung metastases at the first visit and a slower rate of increase than those who did not undergo surgical resection. The maximum diameter and average rate of increase of size of lung metastases were prognostic predictors, whereas primary tumor resection did not significantly affect the outcome.

Various factors such as histological grade have been reported as poor prognostic predictors for bone and softtissue sarcoma (11-13), but few have been reported for patients with distant metastases. Lung metastasis has a worse prognosis than lymph node metastasis, irrespective of therapeutic intervention (1). In our previous study, large 
Table III. Significance of prognostic predictors of survival from the Kaplan-Meier curve.

\begin{tabular}{llc}
\hline Evaluated items & & $p$-Value \\
\hline Gender & Male $v$. female & 0.5815 \\
Location & Extremity $v$ s. axial & 0.5068 \\
Tumor & First time $v$. recurrence & 0.0613 \\
Origin & Soft-tissue $v s$. bone & 0.4278 \\
Histological grade & Low $v$. high & 0.5797 \\
Number of lung metastasis at first visit & $\leq 3 v s .>3$ & 0.2026 \\
Distant metastasis other than lung at the first visit & Yes $v$. no & 0.4240 \\
Surgical treatment for primary tumor & Yes $v s$. no & 0.1118 \\
Radiation for primary tumor & Yes vs. no & 0.6209 \\
Chemotherapy & Yes $v s$. no & 0.6745 \\
Average rate of increase in lung metastasis & $\geq 4.08 v s .<4.08 \mathrm{~mm} / \mathrm{month}$ & 0.0003 \\
Distant metastasis other than lung that appeared later & Yes $v s$. no & 0.6718
\end{tabular}

primary tumor diameter and malignant peripheral nerve sheath tumor were poor prognostic predictors (14), and recently, Zhang et al. showed that tumor size, histological malignancy, and undifferentiated pleomorphic sarcoma were additional ones (8). In our study of patients with only lung metastases, the size at the first visit and the rate of increase were predictors of poor prognosis. Although distant metastases of the lung are the most common, as far as we are aware, there have been no reports that have evaluated only this subset of patients as we have in our study. Thus, when examining the prognosis of bone and soft-tissue sarcoma, it is necessary to focus on lung-metastatic lesions.

A few studies have examined the effect of interventions on patients with bone and soft-tissue sarcoma with distant metastasis. Although some have shown that resection of the distant metastasis improves the prognosis $(2,8,15-17)$, only a few reports have examined the effects of primary lesion resection $(4,5)$. Nakamura et al. showed that prognosis improved after primary lesion excision, but this was through a univariate analysis and they did not examine the treatment for distant metastatic lesions (7). However, Zhang et al. studied more than 1,000 registered cases and reported that primary tumor resection, especially with wide margins, improved prognosis, along with resection of distant metastasis in multivariate analysis (8). In our study, although the analysis was limited to patients with lung metastasis and the number of cases was small, the prognosis was not significantly affected after primary tumor resection. It is important to note that the primary tumor may be aggressively resected to improve the patient's distress, even if there are distant metastases.

The rate of increase in the size of lung metastases was the factor that most affected the prognosis in our study, and it was only associated with the maximum diameter at the first visit. Since the rate of growth of lung metastases is high,

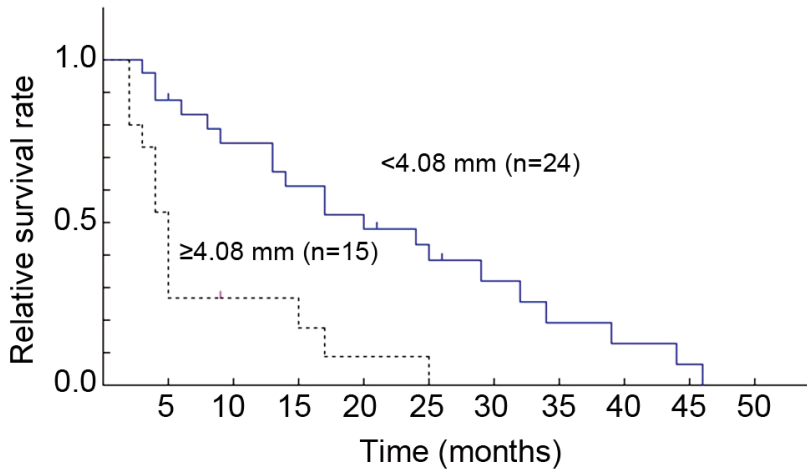

Figure 1. Kaplan-Meier overall survival curves for patients with bone and soft-tissue tumors according to the monthly rate of growth of lung metastases, using a cut-off of $4.08 \mathrm{~mm} / \mathrm{month}$. These curves revealed that patients with slow-growing lung metastases had a significantly better prognosis than those with fast-growing ones ( $p=0.0003)$.

lung metastases may already be large when the primary tumor is diagnosed.

In this study, primary resection was not shown to significantly affect the rate of increase in the size of lung metastases. Yet both the odds ratio and the $p$-value were low. Given the reports that primary tumor resection is a prognostic predictor, it may be possible that it affects the rate of increase in lung metastasis size. However, in this study, the size of lung metastases at the first visit was significantly smaller in patients who had undergone surgical resection. Although we conducted a multivariate analysis, it is possible that the rate of lung metastasis increase was low due to the large number of surgeries performed on patients with small lung-metastatic lesions at the time of the initial diagnosis. In order to better clarify this, more cases need to be examined. 
Table IV. Comparison between patients with fast-and slow-growing lung metastases.

\begin{tabular}{|c|c|c|c|c|}
\hline & & Fast-growing $(\mathrm{n}=15)$ & Slow-growing $(n=24)$ & $p$-Value \\
\hline Age, years & Mean \pm SD & $53.2 \pm 20.9$ & $59.0 \pm 26.5$ & 0.4736 \\
\hline \multirow[t]{2}{*}{ Gender, n (\%) } & Male & $9(60.0)$ & $12(50.0)$ & 0.7800 \\
\hline & Female & $6(40.0)$ & $12(50.0)$ & \\
\hline \multirow[t]{2}{*}{ Location, n (\%) } & Extremity & $11(73.3)$ & $13(54.2)$ & 0.3905 \\
\hline & Axial & $4(26.7)$ & $11(45.8)$ & \\
\hline Size of the primary tumor, $\mathrm{mm}$ & Mean \pm SD & $108.4 \pm 53.7$ & $99.6 \pm 58.5$ & 0.6413 \\
\hline \multirow[t]{2}{*}{ Tumor, n $(\%)$} & First time & $11(73.3)$ & $17(70.8)$ & 0.8439 \\
\hline & Recurrence & $4(26.7)$ & $7(29.2)$ & \\
\hline \multirow[t]{2}{*}{ Origin, n (\%) } & Soft-tissue & $11(73.3)$ & $20(83.3)$ & 0.7302 \\
\hline & Bone & $4(26.7)$ & $4(16.7)$ & \\
\hline \multirow[t]{2}{*}{ Histological grade, n (\%) } & Low & $1(6.7)$ & $1(4.2)$ & 0.6879 \\
\hline & High & $14(93.3)$ & $23(95.8)$ & \\
\hline \multirow[t]{2}{*}{ Number of lung metastases at first visit, $\mathrm{n}(\%)$} & $\leq 3$ & $4(26.7)$ & $13(54.2)$ & 0.1760 \\
\hline & $>3$ & $11(73.3)$ & $11(45.8)$ & \\
\hline Maximum diameter of lung metastasis at first visit, $\mathrm{mm}$ & Mean \pm SD & $19.7 \pm 18.8$ & $8.5 \pm 6.9$ & 0.0419 \\
\hline Average rate of lung metastasis increase, $\mathrm{mm} / \mathrm{month}$ & Mean \pm SD & $8.6 \pm 6.3$ & $1.2 \pm 1.0$ & 0.0005 \\
\hline \multirow[t]{2}{*}{ Distant metastasis other than lung at the first visit, $\mathrm{n}(\%)$} & Yes & $3(20.0)$ & $6(25.0)$ & 0.9760 \\
\hline & No & $12(80.0)$ & $18(75.0)$ & \\
\hline \multirow{2}{*}{ Distant metastasis other than lung that appeared later, $\mathrm{n}(\%)$} & Yes & $2(13.3)$ & $3(12.5)$ & 0.6770 \\
\hline & No & $13(86.7)$ & $21(87.5)$ & \\
\hline \multirow[t]{2}{*}{ Surgical treatment for primary tumor } & Yes & $1(6.7)$ & $8(33.3)$ & 0.1254 \\
\hline & No & $14(93.3)$ & $16(66.7)$ & \\
\hline \multirow[t]{2}{*}{ Radiation for primary tumor, $\mathrm{n}(\%)$} & Yes & $3(20.0)$ & $10(41.7)$ & 0.2950 \\
\hline & No & $12(80.0)$ & $14(58.3)$ & \\
\hline \multirow[t]{2}{*}{ Chemotherapy, n (\%) } & Yes & $12(80.0)$ & $13(54.2)$ & 0.1960 \\
\hline & No & $3(20.0)$ & $11(45.8)$ & \\
\hline & Mean \pm SD & $7.1 \pm 6.7$ & $19.9 \pm 12.8$ & 0.0002 \\
\hline \multirow[t]{2}{*}{ Status at the last follow-up, n (\%) } & Alive with disease & $1(6.7)$ & $4(16.7)$ & 0.6770 \\
\hline & Dead & $14(93.3)$ & $20(63.3)$ & \\
\hline
\end{tabular}

Table V. Multivariate logistic regression analysis for the rate of increase in lung metastasis size.

\begin{tabular}{llll}
\hline Factor & OR & $95 \%$ CI & $p$-Value \\
\hline Age & 0.943 & $0.866-1.028$ & 0.1805 \\
Gender (female) & 2.182 & $0.214-22.272$ & 0.5104 \\
Location (axial) & 0.145 & $0.009-2.468$ & 0.1817 \\
Size of the primary tumor & 1.001 & $0.980-1.022$ & 0.9220 \\
Local recurrence & 1.220 & $0.090-16.552$ & 0.8811 \\
Malignant bone tumor & 1.049 & $0.051-21.430$ & 0.9754 \\
Histological grade (high) & 4.564 & $0.454-45.853$ & 0.1896 \\
Maximum diameter of lung metastasis at first visit & 1.199 & $1.024-1.404$ & 0.0245 \\
Number of lung metastasis at first visit (>3) & 1.818 & $0.137-24.052$ & 0.6499 \\
Distant metastasis other than lung at the first visit & 0.352 & $0.023-5.478$ & 0.1374 \\
Surgical treatment for primary tumor & 0.076 & $0.003-2.274$ & 0.4256 \\
Radiation for primary tumor & 0.288 & $0.013-6.151$ & 0.4018 \\
Chemotherapy & 0.218 & $0.006-7.682$ & \\
\hline
\end{tabular}

CI: Confidence interval; OR: odds ratio.

The size of lung metastases at the first visit and the rate of size increase were found to be poor prognostic predictors, whilst the number of lung metastases was not. Although Ferguson et al. showed that patients have a better prognosis when the number of lung metastases is three or fewer, that was the result of a univariate analysis (10). In our study, we investigated lung metastasis in detail by conducting a multivariate analysis, and there have been no reports in the past 
regarding the rate of lung metastasis increase. It is considered to be a very effective index for evaluation, but the method used for its delamination needs to be improved. It is important to note that the rate of increase was calculated only using the first and last computed tomography images. The rate of increase in the size of lung metastases is not always uniform and they may increase rapidly after tumor progression. Therefore, it is necessary to consider a more detailed evaluation method.

The strength of this study is that it is the first to examine the relationship between primary tumor resection and lung metastasis in detail in patients with bone and soft-tissue sarcoma. However, there are some limitations that should be mentioned. Since the number of patients with bone and softtissue sarcoma with lung metastases was small, they were analyzed together in this study, as were patients with initial and recurrence disease. Although a multivariate analysis was performed, it is better to analyze each group separately. In addition, it was not possible to examine various other histological and chemotherapy types in this analysis. Therefore, further detailed studies are needed with a larger number of patients included.

In conclusion, this study evaluated the impact of primary tumor resection and revealed it to have no effect on the prognosis of patients with lung metastasis of bone and softtissue sarcoma. Thus, the primary tumor should be excised only if it is necessary to improve the patient's quality of life. In addition, it may be necessary to consider detailed evaluation of lung metastases such as the rate of increase in size, since it was shown to affect the prognosis in these patients. Future studies should focus on validating these results by conducting larger studies and improving this evaluation index.

\section{Conflicts of Interest}

The Authors report no conflicts of interest.

\section{Authors' Contributions}

All Authors were involved in the planning and revising for this research. Tsuchie $H$, Nagasawa $H$, Emori $M$, Murahasi $Y$, Mizushima E, and Shimizu J collected the clinical data. Tsuchie $\mathrm{H}$ analyzed the raw data. Tsuchie $\mathrm{H}$ wrote the article. Miyakoshi $\mathrm{N}$ and Yamashita $\mathrm{Y}$ reviewed the article.

\section{References}

1 Ferguson PC, Deheshi BM, Chung P, Catton CN, O'Sullivan B, Gupta A, Griffin AM and Wunder JS: Soft tissue sarcoma presenting with metastatic disease: outcome with primary surgical resection. Cancer 117(2): 372-379, 2011. PMID: 20830769. DOI: $10.1002 /$ cncr. 25418

2 Wigge S, Heißner K, Steger V, Ladurner R, Traub F, Sipos B, Bösmüller H, Kanz L, Mayer F and Kopp HG: Impact of surgery in patients with metastatic soft tissue sarcoma: A monocentric retrospective analysis. J Surg Oncol 118(1): 167-176, 2018. PMID: 29953623. DOI: 10.1002/jso.25115

3 Gadd MA, Casper ES, Woodruff JM, McCormack PM and Brennan MF: Development and treatment of pulmonary metastases in adult patients with extremity soft tissue sarcoma. Ann Surg 218(6): 705-712, 1993. PMID: 8257219. DOI: 10.1097/00000658-199312000-00002

4 Simillis C, Kalakouti E, Afxentiou T, Kontovounisios C, Smith JJ, Cunningham D, Adamina M and Tekkis PP: Primary tumor resection in patients with incurable localized or metastatic colorectal cancer: a systematic review and meta-analysis. World J Surg 43(7): 1829-1840, 2019. PMID: 30903246. DOI: 10.1007/s00268-019-04984-2

5 Ahmed S, Leis A, Fields A, Chandra-Kanthan S, Haider K, Alvi R, Reeder B and Pahwa P: Survival impact of surgical resection of primary tumor in patients with stage IV colorectal cancer: results from a large population-based cohort study. Cancer 120(5): 683-691, 2014. PMID: 24222180. DOI: 10.1002/cncr.28464

6 Seo HS, Song KY, Jung YJ, Park SM, Jeon HM, Kim W, Chin HM, Kim JJ, Kim SK, Chun KH, Kim JG, Lee JH, Lee HH, Kim DJ, Yoo HM, Kim CH, Kim EY, Park CH and Catholic Gastric Cancer Study Group (CGCSG): Radical gastrectomy after chemotherapy may prolong survival in stage IV gastric cancer: A Korean multi-institutional analysis. World J Surg 42(10): 3286-3293, 2018. PMID: 29717344. DOI: 10.1007/s00268-018-4635-5

7 Nakamura T, Katagiri H, Shido Y, Hamada S, Yamada K, Nagano A, Yamada S, Tsukushi S, Ishimura D, Matsumine A, Sudo A and Nishida Y: Analysis of factors for predicting survival in soft-tissue sarcoma with metastatic disease at initial presentation. Anticancer Res 37(6): 3137-3141, 2017. PMID: 28551655. DOI: 10.21873 /anticanres.11671

8 Zhang L, Akiyama T, Fukushima T, Iwata S, Tsuda Y, Takeshita K, Kawai A, Tanaka S and Kobayashi H: Prognostic factors and impact of surgery in patients with metastatic soft tissue sarcoma at diagnosis: A population-based cohort study. Jpn J Clin Oncol 51(6): 918-926, 2021. PMID: 33774673. DOI: 10.1093/jjco/hyab033

9 Coindre JM, Terrier P, Bui NB, Bonichon F, Collin F, Le Doussal V, Mandard AM, Vilain MO, Jacquemier J, Duplay H, Sastre X, Barlier C, Henry-Amar M, Macé-Lesech J and Contesso G: Prognostic factors in adult patients with locally controlled soft tissue sarcoma. A study of 546 patients from the French Federation of Cancer Centers Sarcoma Group. J Clin Oncol 14(3): 869-877, 1996. PMID: 8622035. DOI: 10.1200/JCO.1996.14.3.869

10 Enneking WF, Spanier SS and Goodman MA: A system for the surgical staging of musculoskeletal sarcoma. Clin Orthop Relat Res (153): 106-120, 1980. PMID: 7449206.

11 Weitz J, Antonescu CR and Brennan MF: Localized extremity soft tissue sarcoma: improved knowledge with unchanged survival over time. J Clin Oncol 21(14): 2719-2725, 2003. PMID: 12860950. DOI: 10.1200/JCO.2003.02.026

12 Callegaro D, Miceli R, Bonvalot S, Ferguson P, Strauss DC, Levy A, Griffin A, Hayes AJ, Stacchiotti S, Pechoux CL, Smith MJ, Fiore M, Dei Tos AP, Smith HG, Mariani L, Wunder JS, Pollock RE, Casali PG and Gronchi A: Development and external validation of two nomograms to predict overall survival and occurrence of distant metastases in adults after surgical resection of localised soft-tissue sarcomas of the extremities: a retrospective analysis. Lancet Oncol 17(5): 671-680, 2016. PMID: 27068860. DOI: 10.1016/S1470-2045(16)00010-3 
13 Colding-Rasmussen T, Thorn AP, Horstmann P, Rechnitzer C, Hjalgrim LL, Krarup-Hansen A and Petersen MM: Survival and prognostic factors at time of diagnosis in high-grade appendicular osteosarcoma: a 21 year single institution evaluation from east Denmark. Acta Oncol 57(3): 420-425, 2018. PMID: 28741397. DOI: 10.1080/0284186X.2017.1351620

14 Tsuchie H, Emori M, Miyakoshi N, Nagasawa H, Okada K, Murahashi Y, Mizushima E, Shimizu J, Yamashita T and Shimada Y: Prognostic significance of histological subtype in soft tissue sarcoma with distant metastasis. In Vivo 34(4): 19751980, 2020. PMID: 32606169. DOI: 10.21873/invivo.11994

15 Illuminati G, Ceccanei G, Pacilè MA, Calio FG, Migliano F, Mercurio V, Pizzardi G and Nigri G: Surgical outcomes for liposarcoma of the lower limbs with synchronous pulmonary metastases. J Surg Oncol 102(7): 827-831, 2010. PMID: 20872809. DOI: $10.1002 /$ jso.21706
16 Billingsley KG, Lewis JJ, Leung DH, Casper ES, Woodruff JM and Brennan MF: Multifactorial analysis of the survival of patients with distant metastasis arising from primary extremity sarcoma. Cancer 85(2): 389-395, 1999. PMID: 10023707.

17 Liebl LS, Elson F, Quaas A, Gawad KA and Izbicki JR: Value of repeat resection for survival in pulmonary metastases from soft tissue sarcoma. Anticancer Res 27(4C): 2897-2902, 2007. PMID: 17695468.
Received August 16, 2021

Revised September 27, 2021

Accepted September 29, 2021 